East African Medical Journal Vol. 83 No. 11 November 2006

EXTREME HYPERKALAEMIA SECONDARY TO MALIGNANT URETERIC OBSTRUCTION: CASE REPORT

Y. Ali, MD, Senior Registrar in Urology, Department of Surgery (Division of Urology), R.K. Gupta, MD, Senior Registrar in Nephrology, Department of Nephrology, E.O. Kehinde, MBBS, FRCS, MD, Associate Professor, Department of Surgery (Division of Urology) and K.V. Johnny, MBBS, FRCP (C), FRCP (Lond), FACP, MD, Professor, Department of Nephrology, Mubarak Al Kabeer Hospital and Faculty of Medicine, Kuwait University, Kuwait, P.O Box 24923, 13110, Safat, Kuwait

Request for reprints to: Prof. E.O. Kehinde, Department of Surgery (Division of Urology), Faculty of Medicine, Kuwait University, P.O Box 24923, 13110, Safat, Kuwait

\title{
EXTREME HYPERKALAEMIA SECONDARY TO MALIGNANT URETERIC OBSTRUCTION: CASE REPORT
}

\author{
Y. ALI, R.K. GUPTA, E.O. KEHINDE and K.V. JOHNNY
}

\begin{abstract}
SUMMARY
We report a case of a 42 year old patient who collapsed at an airport departure lounge. The patient was investigated and found to have advanced renal failure with serum potassium $\left(\mathrm{K}^{+}\right)$of $\mathbf{1 0 . 3}$ $\mathrm{mmol} / \mathrm{L}$, creatinine of $3581 \mu \mathrm{mol} / \mathrm{L}$ and urea of $59.9 \mathrm{mmol} / \mathrm{L}$ secondary to obstructive uropathy due to advanced bladder cancer. Although these biochemical changes were thought to be incompatible with life, he made a slow recovery following haemodialysis and insertion of bilateral percutaneous nephrostomy tubes.
\end{abstract}

\section{INTRODUCTION}

Hyperkalaemia is defined as plasma or serum $\mathrm{K}^{+}$ greater than $5.3 \mathrm{mmol} / \mathrm{L}$. Serum $\mathrm{K}^{+}$of $5.3-6.5$ $\mathrm{mmol} / \mathrm{L}$ is considered mild hyperkalaemia, and above $6.5 \mathrm{mmol} / \mathrm{L}$ as severe hyperkalaemia. Extreme hyperkalema is defined as $\mathrm{K}^{+}$greater than $9.0 \mathrm{mmol} / \mathrm{L}$ because such levels of serum $\mathrm{K}^{+}$may be considered incompatible with life, with less than six patients having survived such levels, according to the available medical literature (1-4). We described the successful resuscitation techniques employed in a patient who collapsed at an airport departure lounge and was found to have serum $\mathrm{K}^{+}$of $10.3 \mathrm{mmol} / \mathrm{L}$ in addition to other biochemical abnormalities associated with advanced renal failure.

\section{CASE REPORT}

R.A.A, a 42-year old Egyptian man was brought from the airport departure lounge to the emergency room with a history of sudden loss of consciousness while waiting to board an aircraft. Prior to admission the patient was said to be complaining of bilateral loin pain, obstructive lower urinary tract symptoms, drowsiness, poor appetite, lethargy and generalised weakness for which he attended different hospital casualty departments, where he was given symptomatic treatment. He had urinary schistosomiasis in childhood and was a heavy smoker for about 25 years.

On physical examination he had shallow acidotic breathing. His blood pressure was 140/80 $\mathrm{mmHg}$; pulse was $108 /$ minute and temperature was $38^{\circ} \mathrm{C}$. His consciousness level according to the Glasgow coma scale was 5/15. He was intubated immediately, mechanically ventilated, and admitted to the intensive care unit (ICU).

Initial laboratory investigations results were as follows: haemoglobin; $8.9 \mathrm{gm} / \mathrm{dL}$, platelets; $286 \times$ $10^{9} / \mathrm{L}$, serum $\mathrm{K}^{+} 10.3 \mathrm{mmol} / \mathrm{L}$ (normal range 3.5-5.3), serum creatinine $3581 \mu \mathrm{mol} / \mathrm{L}$ (normal range 60-110) and serum urea $59.9 \mathrm{mmol} / \mathrm{L}$ (normal range 2-6). Arterial blood gas-analysis showed a $\mathrm{pH}$ of 6.8 and other gross abnormal changes (Table 1). ECG showed peak $\mathrm{T}$ wave and supraventricular tachycardia. 
The patient was put on fluid resuscitation, i.v. Rocephine 2g OD and H2-receptor blocker (i.v zantac 50mg 8 hourly) to prevent stress ulcer. Emergency haemofiltration was carried out. Following this, there was a mild improvement in his blood biochemistry and serum $\mathrm{K}^{+}$fell to 9.9 $\mathrm{mmol} / \mathrm{L}$ and serum creatinine fell to $2883 \mu \mathrm{mo} / \mathrm{L}$. Subsequently, the patient had emergency haemodialysis and this resulted in rapid lowering of $\mathrm{K}^{+}$from 9.9 to $5.9 \mathrm{mmol} / \mathrm{L}$ within a 12 hour period (Table 2). Ultrasound of the abdomen, kidneys, ureters and bladder revealed bilateral huge hydronephrosis with loss of parenchyma (left> right), thickened bladder wall and a mass in the bladder.

After resuscitation and haemodialysis, his biochemistry improved and on the third post admission day, bilateral percutaneous nephrostomy
(PCN) tubes were inserted. Following the PCN, the patient had post obstructive diuresis and after seven days, the serum creatinine had stabilised at $170 \mu \mathrm{mol} 1 / \mathrm{L}$ and $\mathrm{K}+$ at $4.3 \mathrm{mmol} / \mathrm{L}$ (Table 2). Creatinine clearance was $10 \mathrm{ml} /$ minute from the left kidney, and $37.4 \mathrm{ml} /$ minute from the right kidney. Bilateral antegrade study through the PCN tubes showed complete bilateral ureteric obstruction at the level of the sacro-iliac joints. Diuretic renogram revealed poor-functioning left kidney, with 12\% function while the right kidney had a function of $88 \%$, with evidence of obstruction on both sides. Ten days after successful resuscitation, under general anaesthesia, cystoscopy revealed a bladder filled with a necrotic mass, which was a non-papillary infiltrating tumour. Biopsies were taken. Examination under general anaesthesia revealed posteriouly indurated and fixed bladder wall.

\section{Table 1}

Changes in blood gases of the patient on admission and with treatment

\begin{tabular}{lcccccc}
\hline Substance & Day 1 & Day 2 & $\begin{array}{c}\text { Day / Time } \\
\text { Day 3 } \\
\text { am }\end{array}$ & $\begin{array}{c}\text { Day 3 } \\
\text { pm }\end{array}$ & Day 4 & Day 5 \\
\hline $\mathrm{PH}$ & 6.8 & 7.17 & 7.20 & 7.20 & 7.2 & 7.3 \\
$\mathrm{PCO}_{2}$ & 5.45 & 38.1 & 45.7 & 35.72 & 38.1 & 31.2 \\
$\mathrm{PO}_{2}$ & 16.29 & 192 & 185 & 154 & 86.8 & 115.6 \\
$\mathrm{HCO}_{3}$ & 13.9 & 13.8 & 18. & 15 & 15.4 & 15.4 \\
$\mathrm{BE}$ & -14 & -13.7 & -9.5 & -11 & -11 & -9.5 \\
$\mathrm{SAO}_{2}$ & 97.8 & 99.2 & 98.8 & 93.5 & 97.8 & \\
\hline
\end{tabular}

$\mathrm{BE}=$ Base Excess

\section{Table 2}

Changes in haematological and biochemistry profiles of the patient on admission with treatment

\begin{tabular}{|c|c|c|c|c|c|c|c|c|}
\hline \multirow[t]{3}{*}{ Substance } & \multicolumn{7}{|c|}{ Day / Time } & \multirow{3}{*}{ Day 32} \\
\hline & Day 1 & Day 1 & Day 1 & Day 1 & Day 2 & Day 3 & Day 6 & \\
\hline & $7.30 \mathrm{am}$ & $11.30 \mathrm{am}$ & $5 \mathrm{pm}$ & 12 midnight & & & & \\
\hline $\mathrm{WBC} \times 10^{9} / \mathrm{L}$ & 27.8 & 24.7 & 23.4 & & 19.6 & 17.6 & 13.1 & 6.7 \\
\hline $\mathrm{Hb}(\mathrm{gm} / \mathrm{dL})$ & 8.7 & 9 & 8.4 & & 8.8 & 8.5 & 10.1 & 10.5 \\
\hline Platelets $10^{9} / \mathrm{L}$ & 253 & 265 & 238 & & 222 & 203 & 225 & 175 \\
\hline BUN (mmol/L) & 59.9 & 44.8 & 42.9 & 29.7 & 31.7 & 33.7 & 7.6 & 6.5 \\
\hline Creatinine $(\mu \mathrm{mol} / \mathrm{L})$ & 3581 & 3236 & 2387 & 2043 & 1776 & 1839 & 170 & 170 \\
\hline Potasium (mmol/L) & 10.3 & $9.9^{*}$ & $6.2^{*}$ & $5.9^{*}$ & 4.6 & 4.8 & 4.5 & 4.3 \\
\hline
\end{tabular}

* rapid reduction of $\mathrm{K}^{+}$level with haemodialysis 
Histology revealed poorly differentiated squamous cell carcinoma of the bladder with schistosoma ova in the bladder wall. Bone scan revealed no scintigraphic evidence of skeletal metastases. CT-scan of the abdomen and the pelvis confirmed bilateral hydronephrosis, (left $>$ right) and a bladder tumour invading the rectum (stage $\mathrm{T} 4 \mathrm{NxMo}$ ). The patient refused definitive treatment planned in our unit (palliative cystectomy and ileal conduit). He opted to return to his native country to continue treatment. He was discharged on day 32 with bilateral PCN tubes, serum creatinine of $170 \mu \mathrm{mol} / \mathrm{L}$ and haemoglobin of $10.5 \mathrm{gm} / \mathrm{dL}$.

\section{DISCUSSION}

Hyperkalaemia is a life threatening, potentially fatal condition, mainly due to severe cardiac arrhythmias and other ECG changes, including asystole which can occur depending on the severity and rapidity of development of the hyperkalaemia, as well as the presence of other electrolytes disorders and whether appropriate and prompt treatment had been carried out (5). Progression from mild to severe hyperkalaemia can lead to benign ECG changes being transformed to lethal arrhythmias. The kidney is the main regulator of serum potassium concentration and hyperkalaemia is, therefore, not a rare condition in the hospitalised patient population, especially those with renal disorders.

$\mathrm{K}^{+}$is the major intracellular cation. The total body content is about $3500 \mathrm{mEq}$ (or $50 \mathrm{mEq} / \mathrm{Kg}$ body weight), $90 \%$ of which is intracellular, and only $2 \%$ of body potassium is in the extracellular fluid. Its concentration is finely regulated by the flux of $\mathrm{K}^{+}$ between the extracellular and intracellular space (internal $\mathrm{K}^{+}$homeostasis). Hyperkalaemia is worsened by the redistribution of potassium between intra-and extracellular compartments caused by acidosis (6). In our patient there was obstructive uropathy, renal shutdown, severe dehydration and acidosis all of which could explain the patient's hyperkalaemia.

Treatment modality for hyperkalaemia varies depending on the severity, the renal function status and whether the patient is oliguric or polyuric (7). Haemodialysis is a correct approach for the treatment of hyperkalaemia in patients with renal failure. Any ECG manifestation more severe than peaked T- wave should be treated with intravenous calcium gluconate to allow cell membrane stabilization (8). Serum $\mathrm{K}^{+}$ may also be reduced by administration of intravenous insulin, together with glucose to prevent hypoglycaemia. Insulin stimulates the Na-K ATPase pump driving $\mathrm{K}^{+}$into the cells. Intravenous sodium bicarbonate decreases serum $\mathrm{K}^{+}$by causing a shift of $\mathrm{K}^{+}$into the cell. The Na-K ATPase pump may also be stimulated by B2 adrenergic receptor agonists. Mild hyperkalaemia may be treated with the administration of cation exchange resins, and in non oliguric patients, frusemide may reduce serum $\mathrm{K}^{+}$by increasing urinary potassium excretion. Life threatening hyperkalaemia $\left(\mathrm{K}^{+}>9 \mathrm{mmol} / \mathrm{L}\right)$ is often drug induced such as those encountered during combined therapy with angiotensin converting enzyme (ACE) inhibitors and spironolactone $(3,4)$. Most cases of extreme hyperkalaemia have been seen in patients on ACE inhibitors and spironolactone, frusemide or encountered as a feature of hyperglycaemia or of poorly managed end stage renal failure (ESRF) (2,3). Exacerbating factors include renal insufficiency or concomitant intake of $\mathrm{K}^{+}$retaining drugs (1). Hence, it has been advocated that the combination of spironolactone and ACE inhibitors should be used with caution, monitored closely in patients with renal insufficiency, intercurrent disease, worsening heart failure, old age, DM or simultaneous intake of other drugs that may cause hyperkalaemia. Furthermore, spironolactone dose above $25 \mathrm{mg}$ / day should be avoided. The highest recorded survivable serum $\mathrm{K}^{+}$was $14 \mathrm{mmol} / \mathrm{L}$, but this may be considered to be iatrogenic in origin since the patient had such high $\mathrm{K}^{+}$level sequel to massive rhabdomyolysis sustained during the trauma of cardiopulmonary resuscitation and external defibrillation as well as prolonged ischaemia (1). Furthermore, this case occurred while the patient was being actively resuscitated in an ICU. Four other cases of extreme hyperkalaemia had serum $\mathrm{K}^{+}$levels of 9.1, 9.3, 9.3, $9.4 \mathrm{mmol} / \mathrm{L}$ and were reported in patients with poorly managed haemodialysis, DM + ESRF, ACE inhibitor and ESRF and on a patient on ACE inhibitor and severe diarrhoea respectively $(2,3,9,10)$. Hence, the case being reported must be about the sixth case in the literature of extreme hyperkalaemia. Our case is unique in that the patient did not have any preexisting renal disease and was not on any medication. This case also demonstrates that, $\mathrm{K}^{+}$level of $>10.0$ $\mathrm{mmol} / \mathrm{L}$ can be considered levels at which a patient may die if not due to cardiac complications like severe 
dysrrhythmia, ventricular fibrillation or asystole, the previously thought cause of death in patients with hyperkalaemia $(11,12)$, but secondary to other associated biochemical changes (Tables 1 and 2). These changes often result in severe loss of consciousness as our patient when first seen with a Glasgow coma scale of five was initially thought to have had a sudden catastrophic cerebrovascular accident or myocardial infarction. For patients with severe or extreme hyperkalaemia, haemodialysis should be regarded as the treatment of choice and started as soon as possible. Effective haemodialysis as our case demonstrates results in rapid lowering of serum $\mathrm{K}^{+}$level in these seriously ill patients.

In conclusion, although hyperkalaemia is a potentially lethal condition, and frequently encountered in hospitalised population, it can be treated successfully by pre-emptive measures prior to embarking on haemodialysis which is the best modality of treatment for severe/extreme hyperkalaemia. Severe electrolyte disturbances may be another cause of death in cases of extreme hyperkalaemia when cardiac dysrrthymia does not result in the death of the patient.

\section{REFERENCES}

1. Tran H.A. Extreme hyperkalaemia. South Med. J. 2005; 98: 729-732.

2. McGuigan J., Robertson S. and Isles C. Life-threatening hyperkalaemia with diarhoea during ACE inhibition. Emerg. Med. J. 2005; 22: 154-155.
3. Esposito C., Bellotti N., Fasoli G., at al. Hyperkalaemia induced ECG abnormalities in patients with reduced renal function. Clin. Nephrol. 2004; 62: 465-468.

4. Schepkens H., Vanholder R., Billiouw J.M. and Lameire N. Life-threatening hyperkalaemia during combined therapy with angiotensin-converting enzyme inhibitors and spironolactone: An analysis of 25 cases. Amer. J. Med. 2001; 110: 438-441.

5. Surawicz B. Hemodialysis and electrocardiographic effect of hypopotassemia: difference in response to slow and rapid increase in concentration of plasma potassium. Amer. Heart J. 1967; 73: 647-664.

6. Wang W. The regulation of the small conductance $\mathrm{K}+$ channel in the apical membrane of rat cortical collecting tubule. Amer. J. Physiol. 1990; 259: 494-502.

7. Allon M. Hyperkalaemia in end-stage renal disease: mechanisms and management. J. Amer. Soc. Nephrol. 1995; 6: 1134-1142.

8. Schwarz A.B. Potassium-related cardiac arrhythmias and their treatment. Angiol. 1978; 29: 194-205.

9. Revert L. Lethal hyperkalaemia associated with severe hyperglycaemia in diabetic patients with renal failure Amer. J. Kidney Dis. 1985: 5: 47-48.

10. Acker C.G., Johnson P.J., Palevsky P.M. and Greenberg A. Hyperkalaemia in hospitalised patients. Arch. Int. Med. 1998; 158: 917-924.

11. Collins A.J., Li S., Ma J.Z. and Herzog C. Cardiovascular disease in end-stage renal disease patients. Amer. J. Kidney Dis. 2001; 38: S26-S29.

12. Manland A.K. Hypokalemia and hyperkalaemia. Med. Clin. North Amer. 1997; 81: 611-639. 